\title{
ACRF Ingest Software Status: New, Current, and Future
}

February 2007

Annette Koontz, for ACRF Engineering Management

Pacific Northwest National Laboratory

PNNL Ingest Developers:

Sutanay Choudhury

Brian Ermold

Krista Gaustad

Annette Koontz

Work supported by the U. S. Department of Energy, Office of Science, Office of Biological and Environmental Research 


\section{Introduction}

The purpose of this report is to provide status of the ingest software used to process instrument data for the Atmospheric Radiation Measurement Program Climate Research Facility (ACRF). The report is divided into 4 sections: (1) for news about ingests currently under development, (2) for current production ingests, (3) for future ingest development plans, and (4) for information on retired ingests.

Readers of this status report may want to consult our current list of instrument mentors at http://www.arm.gov/instruments/mentors.php or our list of software developers at http://engineering.arm.gov/engr/task/developercontacts.stm.

Another useful utility is the current datastream status, presented from the ARM Data Management Facility (DMF) perspective, which can be found at http://c1.dmf.arm.gov/ds/dsview/gui/datastream.php.

Hint: Select the "Login as Guest Account" option. Depending on the speed of your internet connection, it may take a few minutes for the complete display to generate. Datastream status for the current calendar month will be displayed. The legend (visible in the upper right hand area) will help you understand the display. In addition, the number (ideally 24.0) indicates the number of hours of data for the day in question.

For those who are interested in the contents of datastreams generated by ARM software, refer to the data object design files at http://science.arm.gov/tool/dod/showdod.php. 


\section{Contents}

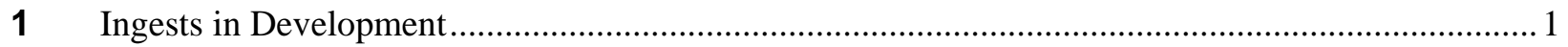

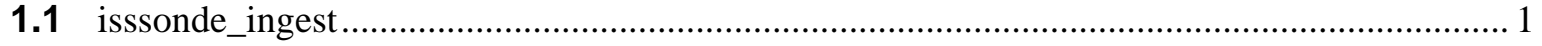

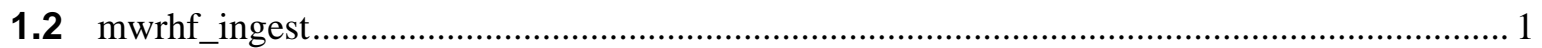

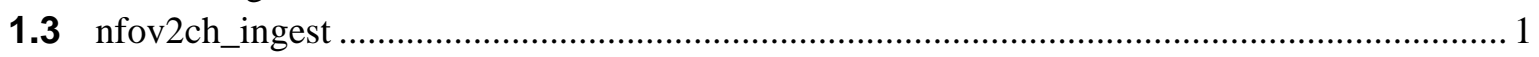

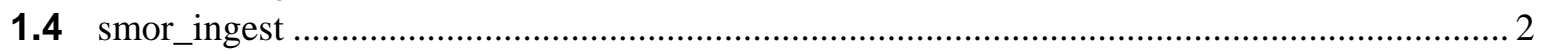

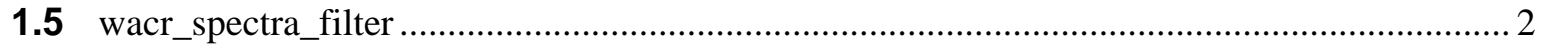

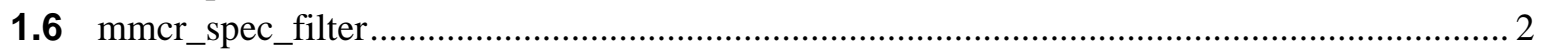

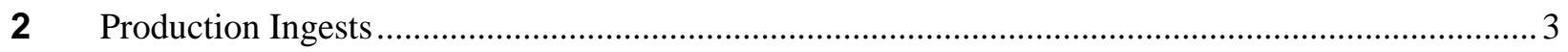

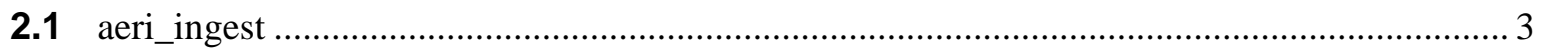

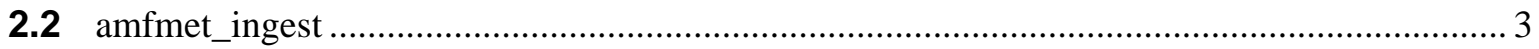

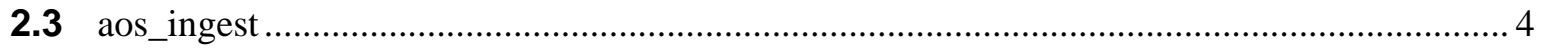

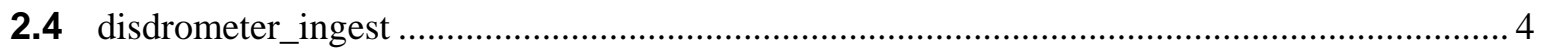

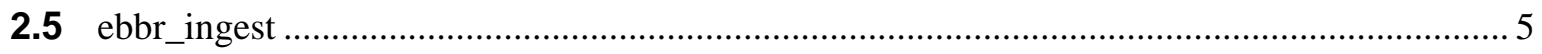

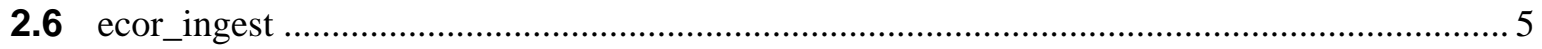

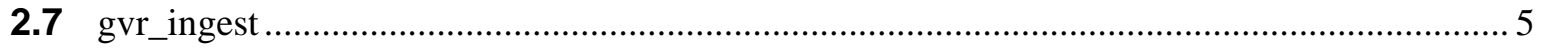

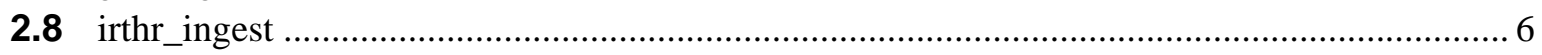

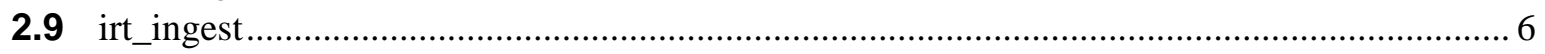

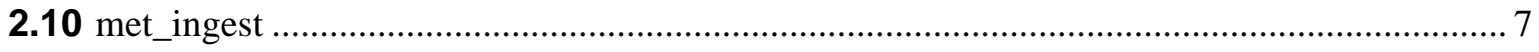

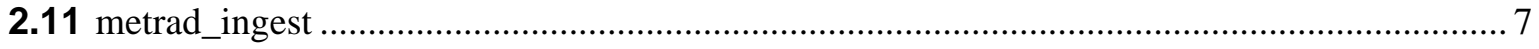

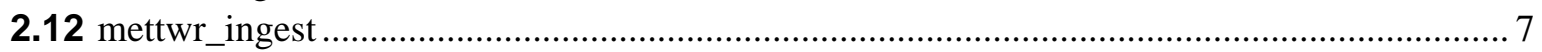

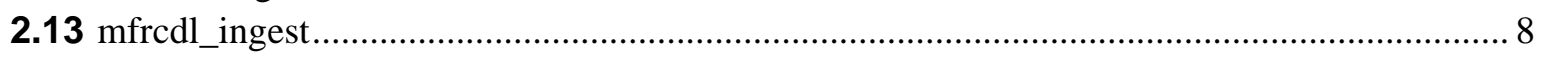

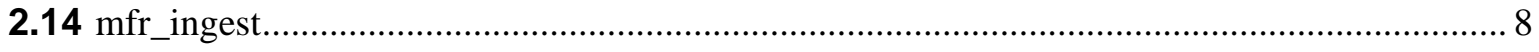

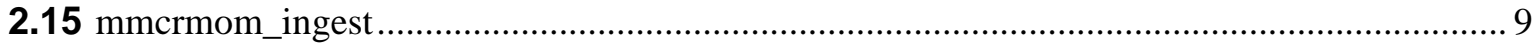

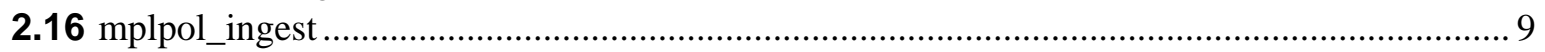

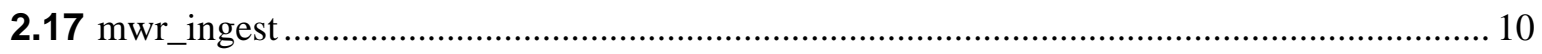

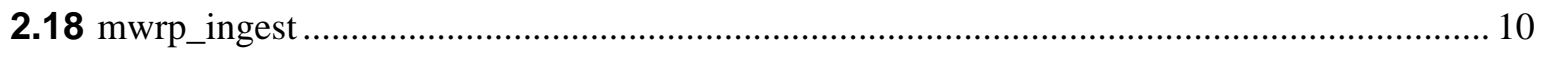

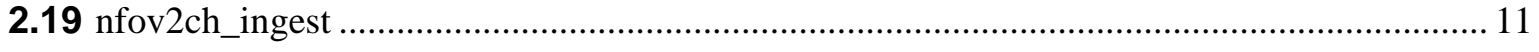

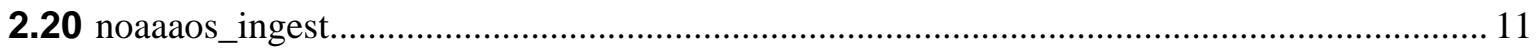

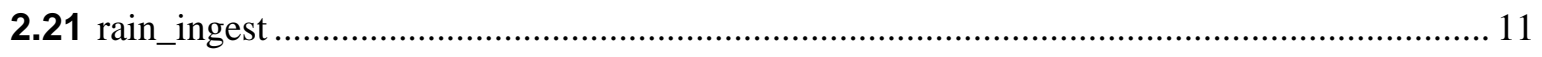

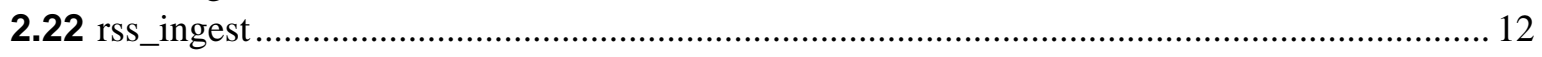

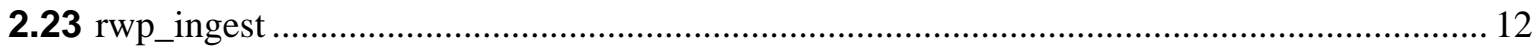

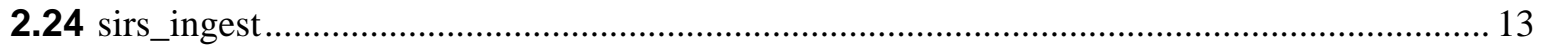

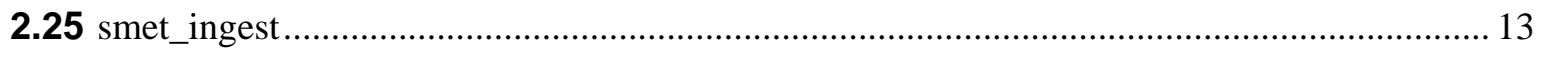

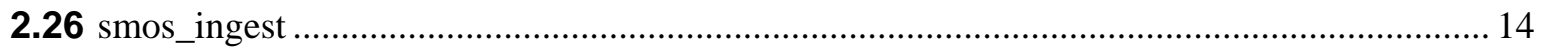

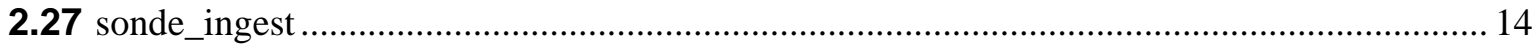

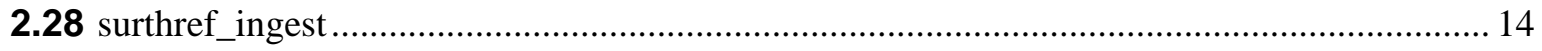

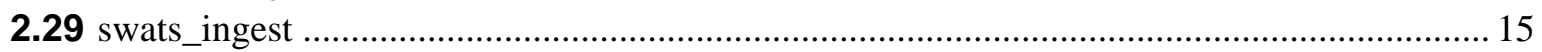

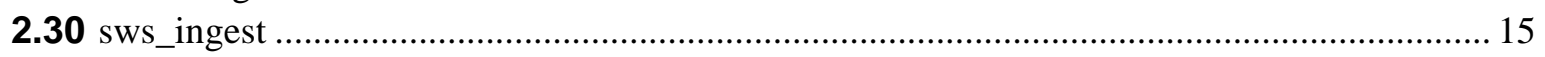

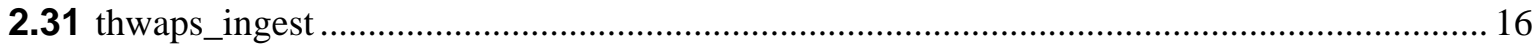

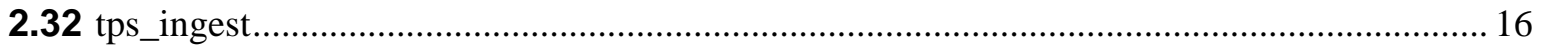

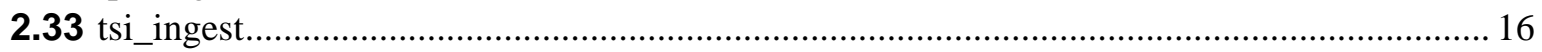

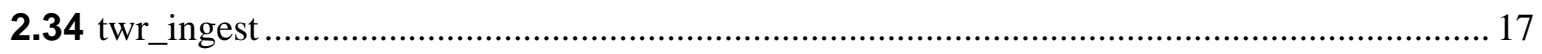

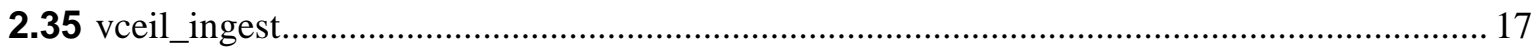

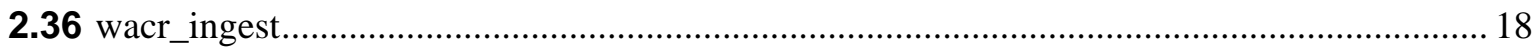




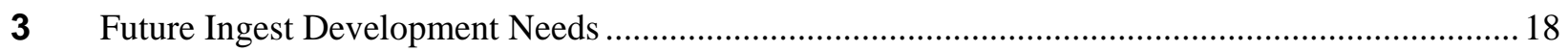

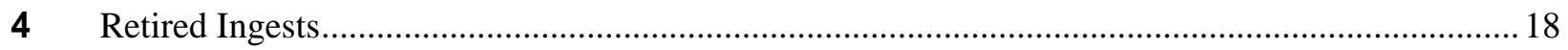

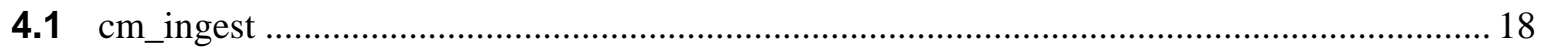

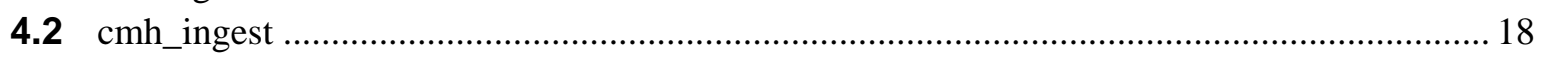

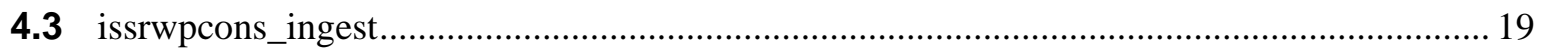

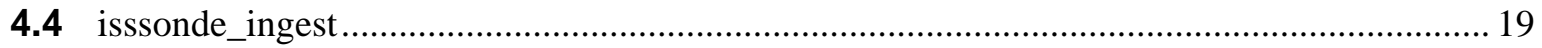

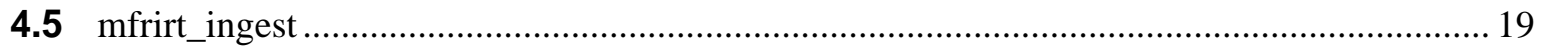

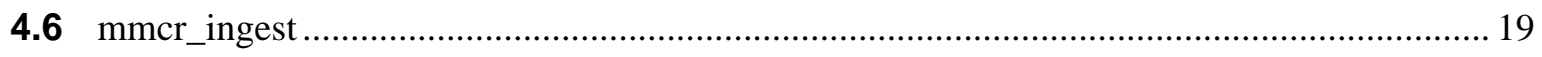

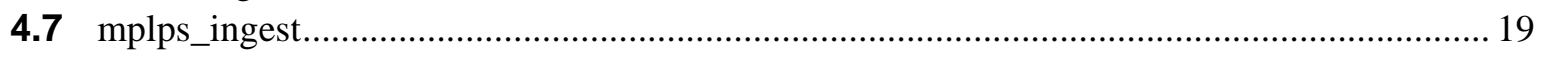




\section{Ingests in Development}

\section{1 isssonde_ingest}

Mentor:

Lead Developer: $\quad$ Barry Lesht

Backup Developer: Brian Ermold

Version:

Status: $\quad$ Retired ingest being revised for historical data processing

Recent BCRs:

\section{Description:}

The isssonde_ingest was used to process sonde data in the past. It is being revised for use with the new databases for the purpose of reprocessing historical data.

\section{2 mwrhf_ingest}

$\begin{array}{ll}\text { Mentor: } & \text { Maria Cadeddu } \\ \text { Lead Developer: } & \text { Sutanay Choudhury } \\ \text { Backup Developer: } & \text { Brian Ermold } \\ \text { Version: } & \text { 1.0-0, 2007/10/29 } \\ \text { Status: } & \text { Running }\end{array}$

Recent BCRs:

\section{Description:}

The mwrhf_ingest will process 90/150-GHz Microwave Radiometer - high frequency (MWRHF) data. This instrument has been installed for a limited time at the Southern Great Plains (SGP) Central Facility (C1).

\section{3 nfov2ch_ingest}

$\begin{array}{ll}\text { Mentor: } & \text { Gary Hodges } \\ \text { Lead Developer: } & \text { Sutanay Choudhury } \\ \text { Backup Developer: } & \\ \text { Version: } & \text { 10.0-2, 2005/06/08 } \\ \text { Status: } & \text { Offline }\end{array}$

Recent BCRs:

\section{Description:}

This ingest is being modified to use new databases. A new release of the nfov2ch_ingest will be ready by the start of the ARM Mobile Facility (AMF) deployment in Germany. 


\section{4 smor_ingest}

Mentor:

Lead Developer: $\quad$ Brian Ermold

Backup Developer: Annette Koontz

Version:

Status:

Retired ingest being revised for reprocessing historical Sky Radiometers on Stand for Downwelling Radiation (SKYRAD) and Ground Radiometers on Stand for Upwelling Radiation (GNDRAD) data

Recent BCRs:

\section{Description:}

This ingest has been taken out of retirement. It will be used for reprocessing of historical SKYRAD and GNDRAD data, but with the addition of logic to use new databases to improve performance and to generate new datastreams comparable to those currently being generated by the sirs_ingest. This reprocessing is needed, at least in part, for subsequent processing by one or more value-added products (VAPs).

\section{5 wacr_spectra_filter}

Mentor:

Lead Developer: $\quad$ Karen Johnson

Backup Developer:

Version:

Status:

Recent BCRs:

\section{Description:}

Similar to the mmcr_spectra_filter, work has begun on software to filter huge spectra files generated by the W-Band (95 GHz) ARM Cloud Radar (WACR). The software will be used to generate spectra files that will be shipped directly to the ARM Archive. The algorithms are being developed by Karen Johnson, Brookhaven National Laboratory (BNL). The work at PNNL is to make the software compatible with the production environment.

\section{6 mmcr_spec_filter}

$\begin{array}{ll}\text { Mentor: } & \text { Karen Johnson } \\ \text { Lead Developer: } & \text { Annette Koontz } \\ \text { Backup Developer: } & \text { Brian Ermold } \\ \text { Version: } & \end{array}$

Status:

Recent BCRs: 


\section{Description:}

The mmcr_spec_filter is a process used to reduce the size of spectra files so that they can be transmitted to the ARM Archive. This software will be released soon to the SGP C1 system for rigorous testing before installation at other sites. We are making final changes to the software. Some additional hardware needs to be installed and configured at the SGP before we can proceed.

\section{Production Ingests}

In the following sections, we will provide very basic information about the ingest software currently running in production. We list the mentor, lead developer, backup developer, basic information about the processing done by the ingest, and the current operational status. Detailed instrument information can be found at http://www.arm.gov/instruments/.

Please note that ingests beginning in "xxx" indicate cases where ingests are ran at multiple ACRF sites, which results in a datastream for each location.

\section{1 aeri_ingest}

$\begin{array}{ll}\text { Mentor: } & \begin{array}{l}\text { Dave Turner } \\ \text { Ralph Dedecker }\end{array} \\ \text { Lead Developer: } & \text { Brian Ermold } \\ \text { Backup Developer: } & \text { Sutanay Choudhury } \\ \text { Current Version: } & \text { 8.0-0, 2006/10/31 } \\ \text { Status: } & \text { Running }\end{array}$

Recent BCRs:

\section{Description:}

The aeri_ingest is used to read raw data generated by the Atmospherically Emitted Radiance Interferometer (AERI). The following datastreams are generated:

sgpaerich1C1.b1, channel 1 data

sgpaerich2C1.b1, channel 2 data

sgpaeriengineerC1.b1, contains engineering data

sgpaerisummaryC1.b1, summary data

\section{2 amfmet_ingest}

$\begin{array}{ll}\text { Mentor: } & \text { Mike Ritsche } \\ \text { Lead Developer: } & \text { Sutanay Choudhury } \\ \text { Backup Developer: } & \text { Brian Ermold } \\ \text { Current Version: } & \text { 2.0-0, 2006/09/07 } \\ \text { Status: } & \text { Offline }\end{array}$

Recent BCRs: 


\section{Description:}

The amfmet_ingest is used to read raw data generated by the AMF surface meteorology measurements. The following netCDF (i.e., network common data format) datastream is generated:

xxxmetM1.b1

\section{3 aos_ingest}

$\begin{array}{ll}\text { Mentor: } & \text { John Ogren } \\ \text { Lead Developer: } & \text { Annette Koontz } \\ \text { Backup Developer: } & \text { Brian Ermold } \\ \text { Current Version: } & \text { 8.0-0, 2006/08/14 } \\ \text { Status: } & \text { Running }\end{array}$

Recent BCRs:

\section{Description:}

The aos_ingest is used to read data generated by the Aerosol Observing Station (AOS) at SGP C1. It generates the following netCDF datastreams:

sgpaosC1.a1

sgpaosauxC1.a0

Sometime in FY2007, the SGP C1 raw data format will be modified to be identical to other AOS instrumentation. At that time, the aos_ingest will be retired and replaced by the noaaaos_ingest.

\section{4 disdrometer_ingest}

$\begin{array}{ll}\text { Mentor: } & \text { Mary Jane Bartholomew } \\ \text { Lead Developer: } & \text { Sutanay Choudhury } \\ \text { Backup Developer: } & \text { Brian Ermold } \\ \text { Current Version: } & \text { 2.0-0, 2006/09/07 } \\ \text { Status: } & \text { Running }\end{array}$

Recent BCRs:

\section{Description:}

The disdrometer_ingest is used to read data from disdrometer instruments. Disdrometers are used to collect data from tipping bucket rain gauges. The following netCDF datastreams are generated:

xxxdisdrometerC1.b1 


\section{5 ebbr_ingest}

$\begin{array}{ll}\text { Mentor: } & \text { David Cook } \\ \text { Lead Developer: } & \text { Sutanay Choudhury } \\ \text { Backup Developer: } & \text { Brian Ermold } \\ \text { Current Version: } & \text { 8.1-0, 2006/09/05 } \\ \text { Status: } & \text { Running }\end{array}$

Recent BCRs:

\section{Description:}

The ebbr_ingest reads data from the Energy Balance Bowen Ratio (EBBR) system. The following datastreams are generated:

xxx5ebbrFn.b1, 5 minute data xxx15ebbrFn.b1, 15 minute data

xxx30ebbrFn.b1, 30 minute data

\section{6 ecor_ingest}

$\begin{array}{ll}\text { Mentor: } & \text { David Cook } \\ \text { Lead Developer: } & \text { Sutanay Choudhury } \\ \text { Backup Developer: } & \text { Brian Ermold } \\ \text { Current Version: } & \text { 8.0, 2006/10/25 } \\ \text { Status: } & \text { Running }\end{array}$

Recent BCRs:

\section{Description:}

The ecor_ingest reads data from the Eddy Correlation Flux Measurement System (ECOR) and generates netCDF datastreams, which provide in situ, half-hour measurements of the surface turbulent fluxes of momentum, sensible heat, latent heat, and carbon dioxide. Datastreams generated include the following:

xxx30ecorFn.b1

\section{7 gvr_ingest}

$\begin{array}{ll}\text { Mentor: } & \text { Maria Cadeddu } \\ \text { Lead Developer: } & \text { Annette Koontz } \\ \text { Backup Developer: } & \text { Brian Ermold } \\ \text { Current Version: } & 1.230, \text { 2007/02/20 } \\ \text { Status: } & \text { Running } \\ \text { Recent BCRs: } & 1344\end{array}$




\section{Description:}

The gvr_ingest reads data generated by the $183.3 \mathrm{GHz}$ radiometer and generates netCDF datastreams. The G-Band Vapor Radiometer (GVR) is located at the North Slope of Alaska (NSA) C1 (Barrow, Alaska) site. Datastreams generated include the following:

nsagvrC1.a0

nsagvrC1.b1

\section{8 irthr_ingest}

$\begin{array}{ll}\text { Mentor: } & \text { Victor Morris } \\ \text { Lead Developer: } & \text { Sutanay Choudhury } \\ \text { Backup Developer: } & \text { Brian Ermold } \\ \text { Current Version: } & \text { 2.0-0, 2006/08/14 } \\ \text { Status: } & \text { Running }\end{array}$

Recent BCRs:

\section{Description:}

The irthr_ingest reads data from the high-resolution infrared thermometer (IRT) instruments distributed around the SGP. Datastreams generated are for 200-millisecond, 2-seconds and 1-minute sample intervals and include the following:

xxxirt200msFn.a1, 200-millisecond data

xxxirt2sFn.b1, 2-second data

xxxirtFn.b1, 1-minute data

\section{9 irt_ingest}

$\begin{array}{ll}\text { Mentor: } & \text { Victor Morris } \\ \text { Lead Developer: } & \text { Annette Koontz } \\ \text { Backup Developer: } & \text { Brian Ermold } \\ \text { Current Version: } & 9.2-0,2006 / 10 / 27 \\ \text { Status: } & \text { Running }\end{array}$

Recent BCRs:

\section{Description:}

The irt_ingest, similar to the irthr_ingest, reads data from the IRT. However, this ingest is designed for the older IRTs that report data every 20 seconds. There is one IRT located on a tower, at 10 meters above the ground, and another at 25 meters above the ground. The tower-mounted instruments are pointed downward. Datastreams generated include the following: 
sgpirt10mC1.b1, 10-meter tower data

sgpirt25m20sC1.a0, 25-meter tower data, 20-second interval

sgpirt25mC1.b1, 25-meter tower data, 1-minute averages

\subsection{0 met_ingest}

Mentor:

Lead Developer: $\quad$ Sutanay Choudhury

Backup Developer: Brian Ermold

Current Version: $\quad$ 7.8-0

Status: Running

Recent BCRs:

\section{Description:}

The met_ingest processed data collected from conventional in situ sensors measuring meteorological data such as wind speed, barometric pressure, and so on. The following datastream is generated:

nimmetM1.b1

\subsection{1 metrad_ingest}

Mentor:

Lead Developer: $\quad$ Sutanay Choudhury

Backup Developer: Brian Ermold

Current Version: $\quad$ 2.0-0, 2006/10/31

Status: $\quad$ Offline

Recent BCRs:

\section{Description:}

The metrad_ingest processes raw METRAD data to produce netCDF files. The datastreams generated include the following:

xxxmetradFn.b1

\subsection{2 mettwr_ingest}

Mentor:

Lead Developer: $\quad$ Brian Ermold

Backup Developer: Sutanay Choudhury

Current Version: $\quad$ 2.1-0, 2006/09/08

Status: Running

Recent BCRs: 


\section{Description:}

The mettwr_ingest processes data collected from conventional in situ sensors on the ground and on a tower at 10 meters and 40 meters above the ground. The sensors measure meteorological data such as wind speed, barometric pressure, and so on. The mettwr_ingest is used to process data collected at NSA from surface and tower meteorological instrumentation. Datastreams generated include the following:

nsamettwr2hC2.b1

nsamettwr4hC2.b1

nsamettwrC1.b1

\subsection{3 mfrcdl_ingest}

Mentor:

Lead Developer: $\quad$ Annette Koontz

Backup Developer: $\quad$ Brian Ermold

Current Version: $\quad 9.2-0,2006 / 10 / 17$

Status: Running

Recent BCRs:

\section{Description:}

The mfrcdl_ingest processes data collected by Multifilter Rotating Shadowband Radiometer (MFRSR) instruments. The datastreams generated include the following:

xxxmfrsrFn.a0

xxxmfrsrFn.b1, processed data

Recently, the MFRSR at the SGP Extended Facility 13 (E13) was converted to the Campbell Data Logger. Raw data are being collected. Ingest via mfrcdl_ingest will resume as soon as the necessary calibration files are generated by the mentor.

\section{$2.14 \mathrm{mfr}$ ingest}

$\begin{array}{ll}\text { Mentor: } & \text { Gary Hodges } \\ \text { Lead Developer: } & \text { Annette Koontz } \\ \text { Backup Developer: } & \text { Brian Ermold } \\ \text { Current Version: } & \text { 7.19-0, 2006/09/18 } \\ \text { Status: } & \text { Running }\end{array}$

Recent BCRs: 


\section{Description:}

The mfr_ingest is used to process Normal Incidence Multifilter Radiometer (NIMFR), Multifilter Radiometer (MFR) 10-meter and 25-meter data. The datastreams generated include the following:

xxxmfr10mFn.a0

xxxmfr10mFn.b1

xxxmfr25mFn.a0

xxxmfr25mFn.b1

xxxnimfrFn.a0

xxxnimfrFn.b1

\subsection{5 mmcrmom_ingest}

$\begin{array}{ll}\text { Mentor: } & \text { Kevin Widener } \\ & \text { Karen Johnson } \\ \text { Lead Developer: } & \text { Annette Koontz } \\ \text { Backup Developer: } & \text { Brian Ermold } \\ \text { Current Version: } & 8.4-0,2006 / 09 / 18 \\ \text { Status: } & \text { Running }\end{array}$

Recent BCRs:

Description:

The mmcrmom_ingest is used to process data from the Millimeter Wavelength Cloud Radar (MMCR). Datastreams generated include the following:

xxxmmcrmomFn.b1

Per Engineering Change Order (ECO) 610, the raw and processed MMCR data will be undergoing another facelift. There is no news on when this will actually happen, but the Engineering Change Request (ECR) has been approved.

\subsection{6 mplpol_ingest}

$\begin{array}{ll}\text { Mentor: } & \text { Richard Coulter } \\ \text { Lead Developer: } & \text { Annette Koontz } \\ \text { Backup Developer: } & \text { Brian Ermold } \\ \text { Current Version: } & 9.1-0,2007 / 02 / 22 \\ \text { Status: } & \text { Running } \\ \text { Recent BCRs: } & 1342 \text { (?) }\end{array}$

Description:

The mplpol_ingest processes data from the Micropulse Lidar. Datastreams generated include the following: 
xxxmplpolFn.b1

Since this data are used by several important “downstream” VAPs, a VAP to average the MPLPOL data has been released and is being run on the DMF. The corresponding averaged datastream names are the following:

xxxmplpolavgFn.c1

xxxmplpolavgFn.s1

Note: Updated to handle some NSA data that was collected during October 2006 and to handle some other rare situations in the raw data. Some SGP, NSA, and Tropical Western Pacific (TWP) C2 data will be reprocessed as a result of enhancements made to the ingest.

\subsection{7 mwr_ingest}

$\begin{array}{ll}\text { Mentor: } & \text { Maria Cadeddu } \\ \text { Lead Developer: } & \text { Annette Koontz } \\ \text { Backup Developer: } & \text { Brian Ermold } \\ \text { Current Version: } & \text { 8.0-0, 2006/08/14 } \\ \text { Status: } & \text { Running }\end{array}$

Recent BCRs:

\section{Description:}

The mwr_ingest processes data from the Microwave Radiometer (MWR). Datastreams generated include the following:

xxxmwrlosFn.b1, line-of-sight data

xxxmwrlosFn.a1, TIP data

\subsection{8 mwrp_ingest}

Mentor:

Lead Developer:

Backup Developer:

Current Version:

Status:

Recent BCRs:

\section{Description:}

The mwrp_ingest processes data collected from the Microwave Radiometer Profiler (MWRP). Datastreams generated include the following:

xxxmwrpFn.b1
Maria Cadeddu

Annette Koontz

Sutanay Choudhury

8.0-0, 2006/08/23

Running 


\subsection{9 nfov2ch_ingest}

$\begin{array}{ll}\text { Mentor: } & \text { Gary Hodges, NOAA } \\ \begin{array}{l}\text { Lead Developer: } \\ \text { Backup Developer: }\end{array} & \text { Sutanay Choudhury, PNNL, } \\ \begin{array}{l}\text { Current Version: } \\ \text { Status: }\end{array} & \begin{array}{l}\text { 10.0-2, 2006/06/08 } \\ \text { Offline }\end{array}\end{array}$

Recent BCRs:

\section{Description:}

The nfov2ch_ingest processes data collected from the Narrow Field of View, 2-channel radiometer (NFOV2). The following datastream is generated:

sgpnfov2chC1.b1

The mentor indicates that the instrument is out for calibration and/or repair. No estimate is available at this time for its return to production. Also, the nfov2ch_ingest is being modified to use new databases and a new version will be released prior to the AMF deployment in Germany.

\subsection{0 noaaaos_ingest}

$\begin{array}{ll}\text { Mentor: } & \text { John Ogren } \\ \text { Lead Developer: } & \text { Annette Koontz } \\ \text { Backup Developer: } & \text { Brian Ermold } \\ \text { Current Version: } & \text { 2.1-0, 2006/09/26 } \\ \text { Status: } & \text { Running }\end{array}$

Recent BCRs

\section{Description:}

The noaaaos_ingest processed raw (not mentor reviewed) data collected from NSA and AMF AOS instruments. Datastreams generated include the following:

xxxaosFn.a0

xxxaosauxFn.a0

xxxaosccnFn.a0

\subsection{1 rain_ingest}

$\begin{array}{ll}\text { Mentor: } & \text { Mary Jane Bartholomew } \\ \text { Lead Developer: } & \text { Sutanay Choudhury } \\ \text { Backup Developer: } & \text { Brian Ermold } \\ \text { Current Version: } & \text { 2.0-0, 2006/09/07 } \\ \text { Status: } & \text { Running } \\ \text { Recent BCRs: } & \end{array}$




\section{Description:}

The rain_ingest is used to process tipping bucket rain gauge data. Datastreams generated include the following:

xxxrainFn.b1

\subsection{2 rss_ingest}

$\begin{array}{ll}\text { Mentor: } & \text { Piotr Kiedron } \\ \text { Lead Developer: } & \text { Brian Ermold } \\ \text { Backup Developer: } & \text { Sutanay Choudhury } \\ \text { Current Version: } & \text { 2.0-0, 2006/10/31 } \\ \text { Status: } & \text { Running }\end{array}$

Recent BCRs:

\section{Description:}

The rss_ingest is used to process data collected from Rotating Shadowband Spectroradiometer (RSS) instruments. The datastreams generated include the following:

xxxrssFn.b1

Note: Data are processed every couple of months, when the required inputs arrive.

\subsection{3 rwp_ingest}

$\begin{array}{ll}\text { Mentor: } & \text { Richard Coulter } \\ \text { Lead Developer: } & \text { Brian Ermold } \\ \text { Backup Developer: } & \text { Sutanay Choudhury } \\ \text { Current Version: } & \text { 8.0-0, 2006/10/25 } \\ \text { Status: } & \text { Running }\end{array}$

Recent BCRs:

\section{Description:}

The rwp_ingest processes data collected from Radar Wind Profilers (RWP). The datastreams generated include the following:

xxx50rwptempFn.a2

xxx50rwptempconFn.a1

xxx50rwptempmomFn.a0

xxx50rwptempspecFn.a0

xxx50rwpwindconFn.a1

xxx50rwpwindmomFn.a0

xxx50rwpwindspecFn.a0 
xxx915rwptempFn.a2

xxx915rwptempconFn.a1

xxx915rwptempmomFn.a0

xxx915rwptempspecFn.a0

xxx915rwpwindconFn.a1

xxx915rwpwindmomFn.a0

xxx915rwpwindspecFn.a0

For the next AMF installation, the rwp_ingest will require modification to handle the new flavor of RWP data.

\subsection{4 sirs_ingest}

$\begin{array}{ll}\text { Mentor: } & \text { Tom Stoffel } \\ \text { Lead Developer: } & \text { Brian Ermold } \\ \text { Backup Developer: } & \text { Sutanay Choudhury } \\ \text { Current Version: } & \text { 10.0-0, 2006/08/31 } \\ \text { Status: } & \text { Running }\end{array}$

Recent BCRs:

\section{Description:}

The sirs_ingest processes data collected from Solar Infrared Radiation Station (SIRS) instruments. Datastreams generated include the following:

xxxsirsFn.b1

xxxsirs20sFn.a0

xxxskyrad60sFn.b1

xxxskyrad20sFn.a0

xxxgndrad60sFn.b1

xxxgndrad20sFn.a0

\subsection{5 smet_ingest}

$\begin{array}{ll}\text { Mentor: } & \text { Michael Ritsche } \\ \text { Lead Developer: } & \text { Brian Ermold } \\ \text { Backup Developer: } & \text { Sutanay Choudhury } \\ \text { Current Version: } & \text { 8.1-0, 2006/10/04 } \\ \text { Status: } & \text { Running } \\ \text { Recent BCRs: } & \end{array}$

Recent BCRs:

\section{Description:}

The smet_ingest processes data collected from Surface Meteorological Instruments for TWP (SMET) data. Datastreams generated include the following: 
xxxsmet60sFn.b1

\subsection{6 smos_ingest}

$\begin{array}{ll}\text { Mentor: } & \text { Michael Ritsche } \\ \text { Lead Developer: } & \text { Brian Ermold } \\ \text { Backup Developer: } & \text { Sutanay Choudhury } \\ \text { Current Version: } & \text { 8.0-0, 2006/08/14 } \\ \text { Status: } & \text { Running }\end{array}$

Recent BCRs:

\section{Description:}

The smos_ingest processes data collected from Surface Meteorological Observation System (SGP version) instruments. Datastreams generated include the following:

xxx1smosFn.b1

xxx30smosFn.b1

The smos_ingest may be updated soon to handle changes being made to the sensors.

\subsection{7 sonde_ingest}

$\begin{array}{ll}\text { Mentor: } & \text { Barry Lesht } \\ \text { Lead Developer: } & \text { Annette Koontz } \\ \text { Backup Developer: } & \text { Brian Ermold } \\ \text { Current Version: } & \text { 8.1-0, 2006/09/28 } \\ \text { Status: } & \text { Running } \\ \text { Recent BCRs: } & \end{array}$

\section{Description:}

The sonde_ingest processes data collected from Balloon-Borne Sounding System (sonde). Datastreams generated include the following:

xxxsondewnpnFn.b1

\subsection{8 surthref_ingest}

$\begin{array}{ll}\text { Mentor: } & \text { Michael Ritsche } \\ \text { Lead Developer: } & \text { Sutanay Choudhury } \\ \text { Backup Developer: } & \text { Brian Ermold } \\ \text { Current Version: } & \text { 2.0-0, 2006/11/01 } \\ \text { Status: } & \text { Running }\end{array}$

Recent BCRs: 


\section{Description:}

The surthref_ingest processes data collected from Surface Temperature and Humidity Reference (SURTHREF) system instruments. Datastreams generated include the following:

xxxsurthrefFn.b1

\subsection{9 swats_ingest}

$\begin{array}{ll}\text { Mentor: } & \text { John Harris } \\ \text { Lead Developer: } & \text { Brian Ermold } \\ \text { Backup Developer: } & \text { Sutanay Choudhury } \\ \text { Current Version: } & \text { 10.0-0, 2006/09/07 } \\ \text { Status: } & \text { Running }\end{array}$

Recent BCRs:

\section{Description:}

The swats_ingest processes data collected from the Soil Water and Temperature System (SWATS). Datastreams generated include the following:

xxxswatsFn.b1

xxxswatsspcpFn.b1

\subsection{0 sws_ingest}

$\begin{array}{ll}\text { Mentor: } & \text { John Pommier } \\ \text { Lead Developer: } & \text { Sutanay Choudhury } \\ \text { Backup Developer: } & \text { Brian Ermold } \\ \text { Current Version: } & \text { 2.0-0, 2006/06/19 } \\ \text { Status: } & \text { Offline }\end{array}$

Recent BCRs:

\section{Description:}

The sws_ingest processes data collected from the Shortwave Spectroradiometer (SWS). Datastreams generated include the following:

xxxswsFn.b1

xxxswsausFn.b1

Note: The sws_ingest is being modified to handle new calibration logic. A new release is expected by the end of February 2007. 


\subsection{1 thwaps_ingest}

$\begin{array}{ll}\text { Mentor: } & \text { Michael Ritsche } \\ \text { Lead Developer: } & \text { Brian Ermold } \\ \text { Backup Developer: } & \text { Sutanay Choudhury } \\ \text { Current Version: } & \text { 8.0-0, 2006/08/14 } \\ \text { Status: } & \text { Running }\end{array}$

Recent BCRs:

\section{Description:}

The thwaps_ingest processes data collected from Temperature, Humidity, Wind and Pressure Sensors (THWAPS) instruments. Datastreams generated include the following:

xxxthwapsFn.b1

\subsection{2 tps_ingest}

$\begin{array}{ll}\text { Mentor: } & \text { Mark Ivey } \\ \text { Lead Developer: } & \text { Sutanay Choudhury } \\ \text { Backup Developer: } & \text { Brian Ermold } \\ \text { Version: } & \text { 1.0-0, 2006/12/22 } \\ \text { Status: } & \text { Running }\end{array}$

Recent BCRs:

\section{Description:}

The Total Precipitation Sensor (TPS) will be deployed at both NSA sites in Barrow and Atqasuk, Alaska, soon. The tps_ingest will process data from the Total Precipitation Sensor (precipitation rate and daily accumulated precipitation).

\subsection{3 tsi_ingest}

$\begin{array}{ll}\text { Mentor: } & \text { Victor Morris } \\ \text { Lead Developer: } & \text { Sutanay Choudhury } \\ \text { Backup Developer: } & \text { Brian Ermold } \\ \text { Current Version: } & \text { 10.1-0, 2006/11/07 } \\ \text { Status: } & \text { Running }\end{array}$

Recent BCRs:

\section{Description:}

The tsi_ingest processes data collected from the Total Sky Imager (TSI). Datastreams generated include the following:

xxxtsicldmaskFn.a1 
xxxtsimovieFn.a

xxxtsiskycoverFn.b1

xxxtsiskyimageFn.a1

\subsection{4 twr_ingest}

$\begin{array}{ll}\text { Mentor: } & \text { David Cook } \\ \text { Lead Developer: } & \text { Brian Ermold } \\ \text { Backup Developer: } & \text { Sutanay Choudhury } \\ \text { Current Version: } & \text { 8.0-0, 2006/09/07 } \\ \text { Status: } & \text { Running }\end{array}$

Recent BCRs:

\section{Description:}

The twr_ingest processes data collected from meteorological instruments located on towers above the ground. The datastreams generated include the following:

xxx1440twr21xFn.b1

xxx1440twr25mFn.b1

xxx1440twr60mFn.b1

xxx1twr10xFn.b1

xxx1twr25mFn.b1

xxx1twr60mC1.b1

xxx30twr10xFn.b1

xxx30twr25mFn.b1

xxx30twr60mFn.b1

\subsection{5 vceil_ingest}

$\begin{array}{ll}\text { Mentor: } & \text { Victor Morris } \\ \text { Lead Developer: } & \text { Brian Ermold } \\ \text { Backup Developer: } & \text { Annette Koontz } \\ \text { Current Version: } & \text { 8.1-0, 2006/09/08 } \\ \text { Status: } & \text { Running }\end{array}$

Recent BCRs:

\section{Description:}

The vceil_ingest processes data collected from Vaisala Ceilometers (VCEILs). Datastreams generated include the following:

xxxvceil25kFn.b1 


\subsection{6 wacr_ingest}

$\begin{array}{ll}\text { Mentor: } & \text { Kevin Widener } \\ \text { Lead Developer: } & \text { Annette Koontz } \\ \text { Backup Developer: } & \text { Brian Ermold } \\ \text { Current Version: } & \text { 8.1-0, 2006/09/11 } \\ \text { Status: } & \text { Running }\end{array}$

Recent BCRs:

\section{Description:}

The wacr_ingest processes data collected from W-Band (95 GHz) ARM Cloud Radar (WACR) instruments. Datastreams generated include the following:

xxxwacrFn.b1

\section{Future Ingest Development Needs}

In the next few weeks, the underlying libraries used by the ingests will be updated to further standardize the quality check (QC) results and make QC attributes more consistent with recent VAP QC standards.

In future months, the latest generation of database software used by the ingest software will continue to be developed.

\section{Retired Ingests}

This section lists ingest software that has been retired from production.

\section{1 cm_ingest}

The $\mathrm{cm}$ _ingest processed data collected from chilled mirror instrumentation at SGP. It produced the following datastreams:

sgpcmC1.b1

sgpcm25mC1.b1

sgpcm60mC1.b1

\section{2 cmh_ingest}

The cmh_ingest processed data collected from chilled mirror hygrometer instrumentation the NSA Barrow (C1) and Atqasuk (C2) facilities. It produced the following datastreams:

nsacmhC1.b1

nsacmhC2.b1 


\section{3 issrwpcons_ingest}

The issrwpcons_ingest was used to process data from an external rass wind profiler (RWP) located at TWP. It produced the following datastreams:

twp915issrwptempconX1.a1

twp925issrwpwindconX1.a1

\section{4 isssonde_ingest}

The isssonde_ingest was used to process data from balloon-borne radiosondes located at NSA C1. It produced the following datastreams:

nsaisssonde10sC1.a1

nsaisssonde10sC1.b1

nsaisssondeC1.a1

\section{5 mfrirt_ingest}

The mfrirt_ingest was used to process data collected from an IRT instrument that was included in an MFR datastream at SGP C1. It produced the following datastreams:

sgpmfrirt10mC1.b1

sgpmfrirt25mC1.b1

Note: This data has all been reprocessed and cloned to look like sgpirt10mC1.b1 and sgpirt25mC1.b1 data.

\section{6 mmcr_ingest}

The mmcr_ingest has been replaced by the mmcrmom_ingest. The mmcr_ingest was used to process data collected from the first generation of MMCR instruments. It produced the following datastreams:

sssmmcrcalFn.a1

sssmmcrmomentsFn.a1

sssmmcrmonFn.a1

sssmmcrpowFn.a1

\section{7 mplps_ingest}

The mplps_ingest was used to process data collected from a prototype polarizing MPL located at NSA C1. It produced the following datastream:

nsamplpsC1.a0 
This data was subsequently used as input to the mplavg process, which produced nsamplC1.a1. This data was used as input to the ARSCL VAP.

This ingest was retired when the mplpol_ingest was put into production at NSA C1. 